\title{
MEDIOS AUDIOVISUALES UTILIZADOS EN LA ENSEÑANZA EN LA CARRERA DE ZOOTECNIA
}

Consuelo Lizeth Blandón Jirón ${ }^{[1]}$

Claribel del Rosario Castillo Úbeda ${ }^{[2]}$

\section{Resumen}

Se abordó los tipos de medios audiovisuales en el proceso formativo, las destrezas e importancia que le dieron tanto educandos como docentes, a través del uso apropiado de retroproyectores, computadoras, televisores, grabadoras, rota-folios, pizarrones en la carrera de Zootecnia, URACCAN, Recinto Nueva Guinea, II semestre 2008.

El enfoque fue cualitativo y descriptivo, enmarcado en referir el uso de los medios audiovisuales empleados por el personal docente en la carrera de zootecnia, que junto a la comunidad estudiantil conformaron nuestra unidad de análisis. Es de carácter transversal, segundo semestre del 2008. La información se obtuvo a través de la observación, entrevistas y grupos focales.

Los hallazgos indicaron que la oportuna administración de medios audiovisuales en la docencia permite la consolidación de un aprendizaje significativo siempre y cuando se enfoque a la formación integral del individuo.

Se comprobó que la planta docente está consciente de la relevancia de estas herramientas al momento de facilitar sus conferencias o escuchar las ponencias realizadas por la comunidad estudiantil. Sin embargo, aunque los equipos se encuentren disponibles, en la mayoría de las ocasiones hay cierta resistencia a su utilización.

Palabras Claves: Enseñanza, medios audiovisuales, estrategia, tecnología, calidad, didáctica.

\section{Introducción}

El vertiginoso avance adquirido en la tecnología de esta era, facilita la participación dinámica y dialéctica de los principales sujetos de la educación en una significativa comprensión y transformación de la realidad.

A finales de la década de 1940 la UNESCO impulsó la educación audiovisual en todo el mundo. En noviembre de 1947, al celebrarse en México la Segunda Conferencia General de esta organización, la delegación mexicana presentó un informe entitulado:

[1] MSc. en Ciencias Sociales. Responsable de Registro Académico de la URACCAN, Recinto Universitario Nueva Guinea. consuelouraccan@gmail.com

[2] Tutora en la investigación. MSc. en Ciencias Sociales. Vicerrectora de la URACCAN, Recinto Universitario de Nueva Guinea. 
La educación audiovisual, fines y organización internacional, donde se subraya la relevancia e impacto de su uso en el sistema educativo.

Cabera (1999) entre otros, afirma que las herramientas tecnológicas fortifican la disciplina educativa en forma viva, polisémica y significativa.

La Universidad de las Regiones Autónomas de la Costa Caribe Nicaragüense, URACCAN, ha requerido que la planta docente y los estudiantes de la carrera de Ingeniería en Zootecnia utilicen esos instrumentos tecnológicos con distintos fines y propósitos, pero siempre dirigidos a la práctica educativa.

Constituye interés describir si por medio de esos equipos (retroproyectores, televisores, VHS, Data-Show, DVD, computadoras, rota-folios, entre otros), los docentes proponen nuevas realidades, diversos problemas, construyen situaciones relevantes, forman actitudes, forjan valores, aplican y explican con discrecionalidad el conjunto de saberes conceptuales y actitudinales en sus estudiantes, principios de la URACCAN.

La importancia del uso de medios audiovisuales en la enseñanza de la Educación Superior radica en el interés por lograr cambios evidentes, tanto en la forma de interactuar dentro del aula como en la manera de poner en práctica lo aprendido, y lograr que los procesos formativos, devengan en el bienestar de una ciudadanía comprometida societariamente con el bienestar de la civilización.

La utilización acertada de los medios audiovisuales, hace posible el afianzamiento del aprendizaje por medio de imágenes y sonidos, se potencia la creatividad, el pensamiento crítico y propositivo. Se monitorea la frecuencia del uso de los medios audiovisuales utilizados por los docentes, así como las destrezas en el manejo y la calidad de cuanto presentan, con el fin de determinar si la interacción entre estudiante $\mathrm{y}$ docentes reintegran su funcionalidad en razón de su aplicabilidad.

\section{Revisión de literatura}

La tecnología de los medios audiovisuales pautan el conocimiento recíproco entre los docentes y discentes de manera activa (Poole, 1991).

\section{Educación con medios audiovisuales}

Históricamente se han estudiado diferentes paradigmas socioculturales sobre la línea de la educación. Es así que en la didáctica, no hay que perder de vista que los instrumentos (o mediadores psicológicos utilizados en la educación) deben servir para ordenar y posicionar la información, de modo de facilitar el desarrollo del lenguaje simbólico sobre el cual se construye el pensamiento y el conocimiento científico (Castaño, 1992). 
Cuando los recursos audiovisuales fuesen utilizados para captar el interés de los educandos distraídos, o cuando su uso no vaya unido al contacto dialéctico en el aula, nos estaríamos alejando del objetivo educacional (Ibíd.).

Según Cebrian (200o), para un óptimo aprovechamiento de los medios audiovisuales es necesario que se den conjuntamente tres elementos a saber: el equipamiento audivisual completo, calidad del manejo de los medios y competencia en el uso de los medios por docentes y estudiantes.

\section{Enfoque teórico-pedagógico}

Existe multitud de corrientes en lo que se refiere a educación. El enfoque pedagógico tradicional es una de esas, que está "caracterizada por ser en términos generales autoritaria, jerárquica, centrada en el maestro, memorística, acrítica, dogmática y alejada de la vida de los estudiantes" (Chávez, 1999, p. 201).

La corriente pedagógica o "transmisionismo conductista" como la denominara Flores, R. (1988), está representada en la Tecnología Educativa surgida en Colombia entre 1960 y 1970 . Ésta nace en torno a la modernización del sector productivo a favor del sistema económico capitalista.

La otra corriente pedagógica es la cognitivista, enfatiza en el desarrollo, afianzamiento y optimización de las habilidades del conocimiento del estudiante y su crucial ascenso a niveles superiores a partir de las nociones básicas. Desde el modelo pedagógico que sugiere esta corriente, se pretende que el estudiante logre una preparación que le permita conocer y reconocer -metacognición le denominan- los procesos y habilidades que se requieren para aprender.

Es importante que los docentes conozcan y utilicen las herramientas básicas de la tecnología y empleen los buscadores en Internet, el chat y el foro con criterios para seleccionar los medios a utilizar.

\section{La comunicación en la educación}

No puede hablarse de verdadera enseñanza si no existe la comunicación, pues debe existir empatía entre docente y discente para que el proceso educativo se consuma, debe ser horizontal para retroalimentar y disfrutar los saberes (Aguilar, 1992).

\section{Manejo de los medios audiovisuales}

En el caso del medio informático las ideas de desplazamiento y recuperación de medios anteriores son evidentes, por los lenguajes audiovisuales y escritos, que sintetiza e incorpora a su propio modelo de expresión. Es aquí donde se enmarca nuestro perfil de 
investigación, porque es mejor y todavía aún más efectivo facilitar clases manipulando medios audiovisuales para que el estudiantado se apropie tanto del conocimiento científico como del uso del medio, pues éste hace pertinente la educación en las aulas de clase (Gardner, 2002).

La simbolización a la que está sujeto el individuo, implica que "los seres humanos están tan 'preparados' para tener injerencia en procesos simbólicos desde el lenguaje hasta los sueños (Gardner, 1987).

\section{Medios didácticos}

La didáctica es el arte de enseñar, tomando en cuenta los medios que son indispensables en la educación. Como recursos para la enseñanza de la expresión audiovisual y escrita, los docentes y estudiantes pueden organizar el análisis y reflexión sobre la propia realidad educativa, u otro tema de su entorno, con géneros como el debate, la crítica, el reportaje, la crónica, la encuesta, etc.

En la actualidad existe una diversidad de tecnologías flexibles y sofisticadas que van desde medios analógicos hasta digitales, desde aquello en que el sujeto es mero receptor pasivo de sus mensajes hasta lo que facilitan una interacción con los usuarios (Cabero, 1999, pp. 281-282).

\section{Materiales y métodos}

El enfoque se guió por el paradigma cualitativo y se enmarcó en el monitoreo del uso de los medios audiovisuales por parte de los docentes con el fin de establecer patrones de comportamiento, actitud, manipulación y verificar la teoría recopilada a través del análisis documental; según el alcance fue descriptiva por medio de la revisión documental efectuada, y con la recopilación de los datos a través de los instrumentos aplicados tanto a docentes como discentes, este estudio posee un corte transversal, segundo semestre del 2008, en la carrera de Ingeniería en Zootecnia de la URACCAN.

\section{Resultados y discusión}

\section{Importancia del uso de medios audiovisuales que le imprimen los docentes en sus clases}

Efectividad en el uso y manejo de los medios audiovisuales en el proceso enseñanza aprendizaje, se inicializa desde la conceptualización de los medios audiovisuales que tienen los docentes y estudiantes entrevistados. 
Ambos sujetos están claros de la utilización de dichos instrumentos y cuál es en sí su fin, aunque en la práctica se utilizan pocos, los docentes han sido capacitados para darle buen uso y manejo a los mismos, por parte de la Universidad URACCAN, recinto Nueva Guinea.

Los docentes y estudiantes tienen conocimientos básicos sobre las definiciones relacionadas a los medios audiovisuales, y reflejan coincidencias teóricas. Los docentes entrevistados y los estudiantes en los grupos focales coincidieron en la definición de medios desde cada punto de vista de la siguiente forma:

Es el tipo de apoyo para realizar charlas, capacitaciones, entrevistas, conferencias e incluso una sesión de clase; ayuda a desarrollar las habilidades del estudiante para que el conocimiento sea profundizado y aprovechado por medio de lo que observó para consolidar el proceso de Enseñanza. (Docentes entrevistados).

Los estudiantes que fueron parte del grupo focal aseveran que "Los medios audiovisuales son los instrumentos que se utilizan para brindar información a las personas y así adquirir mayores conocimientos concretos".

Si analizamos estos conceptos extraídos de las entrevistas y grupos focales conformados por docentes y estudiantes, nos daremos cuenta que los docentes abordan el concepto de medios audiovisuales desde el punto de vista de la didáctica, pues señalan que "es el apoyo para lograr el proceso de enseñanza aprendizaje". Al revisar lo expuesto por los estudiantes esto lo enfocan desde "la obtención de la información". Cada uno tiene una concepción diferente según corresponde al fin que persiguen.

De acuerdo con los resultados obtenidos del grupo focal con docentes y estudiantes, conocen en primer orden y con mayor porcentaje el Data-Show y el retroproyector. El DVD está con un porcentaje mínimo en relación con el anterior, el cual ha sido sustituido por el Data-Show; el televisor, el papelógrafo y la pizarra en una escala menor.

El 25\% de los docentes observados usan el Data-Show y el retroproyector, mientras que el $37.5 \%$ usaron otros medios como plantas (material concreto) las que se presentan de forma físicas en el aula de clase, donde los estudiantes entran en contacto directo, los palpan, manipulan, estudian e identifican. Los docentes alcanzan sus objetivos al trasladar una planta a la sala de clase, porque logra el aprendizaje significativo en el estudiante. Otros usaron dibujos.

\section{Frecuencia con que utilizan los docentes los medios audiovisuales en los salones de clase}

Los docentes usan los medios audiovisuales con frecuencia y cuando están disponibles, porque no existe la cantidad necesaria en la universidad URACCAN, Recinto 
Universitario Nueva Guinea. Sin embargo, los docentes tratan de proyectar en la medida de lo posible algunos temas que pueden desarrollarse con determinado medio.

Es de suma importancia que los docentes preparen sus clases utilizando medios audiovisuales, tomando en cuenta que estén capacitados en el manejo de los medios con respecto a su instalación, cuido, desinstalación, entre otros, y que les den el debido uso y no abuso al medio, recordando que los medios audiovisuales son herramientas para la enseñanza y esto no sustituye al docente.

Al analizar el Gráfico número 3, los docentes al instalar y desinstalar los equipos, nos daremos cuenta que del $100 \%$, solamente el $25 \%$ fueron capaces de valerse de sus propios conocimientos sin contar con la ayuda del informático o de otra persona. (ver gráfico No. 3)

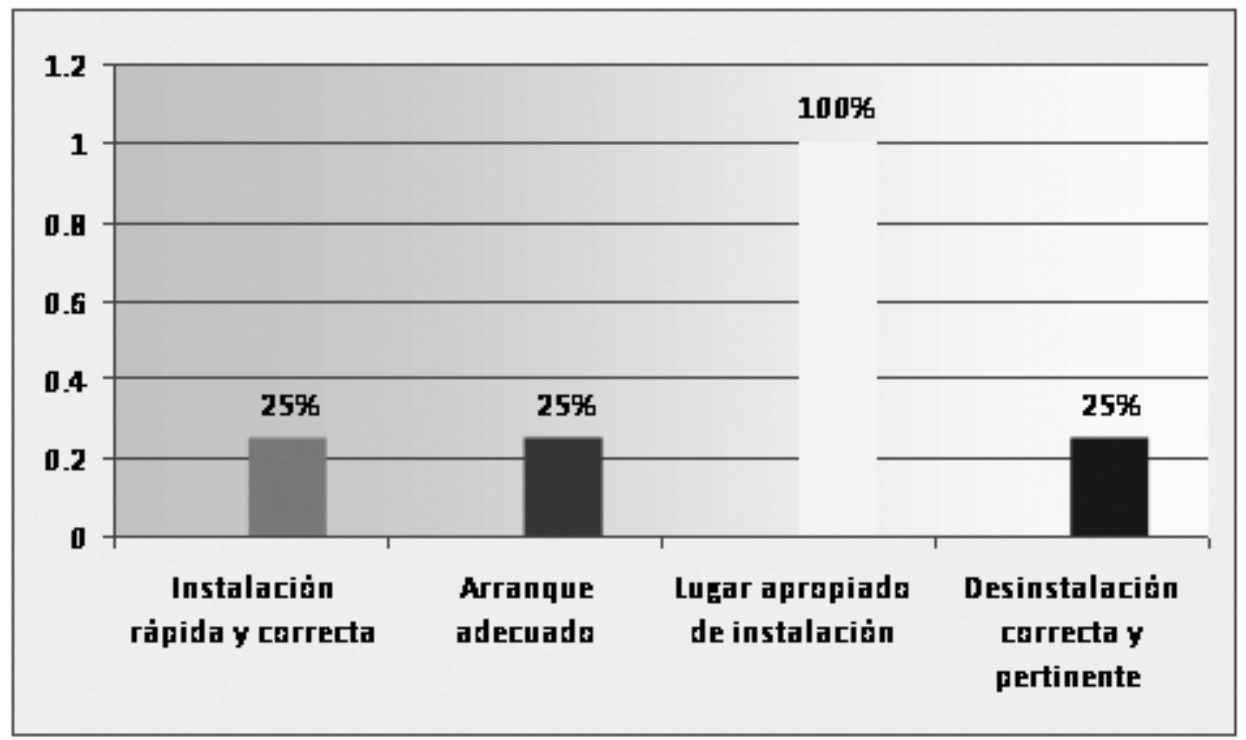

Gráfico No. 3: Uso de los medios audiovisuales en la sala de clase por docentes

Los docentes deben estar actualizándose constantemente, para que la globalización no atrase el proceso educativo por falta de dominio ante el uso de los medios audiovisuales, o en el peor de los casos, actitud de rechazo ante los nuevos sistemas tecnológicos.

\section{Actitud del docente al manipular medios audiovisuales en el proceso enseñanza}

Este capítulo se refiere a la actitud asumida por el docente desde el momento en que ha preparado sus clases. De igual manera se valora la actitud y el dinamismo de los 
sujetos en el salón y durante el desarrollo de los contenidos. Es decir, de qué manera propicia el espacio de integración del estudiante en el proceso enseñanza.

A partir de las observaciones efectuadas, se comprueba que el $75 \%$ de los docentes trabajaron dirigiendo preguntas y fomentan comentarios, asimismo se generan espacios de confianza para interactuar en la reflexión y análisis de las temáticas abordadas. En contraposición de un $25 \%$ que optaron por una vía más cómoda, dejando que sus presentaciones hablaran por sí mismas, sin propiciar el debate.

Se observó que, aun cuando los docentes hicieron preguntas y animaron el diálogo o el debate con el resto de los estudiantes, éstos no se vieron motivados a participar. Se infiere que las láminas estaban recargadas de textos, los colores de las diapositivas eran opacas, y hasta el tamaño y estilo de fuentes no estimulaban la atenta lectura. Y, aunque, los docentes hayan demostrado dominio en la manipulación de los medios audiovisuales, la forma en que fueron presentadas sus ideas no correspondía con las normas básicas para motivar al auditorio.

Se logró comprobar que los docentes en su totalidad preparan con anticipación los contenidos de sus clases, y definen en sus planes las estrategias (trabajos en equipos, ponencias, clases prácticas, etcétera) para motivar a los estudiantes a una participación activa en función del desarrollo de sus objetivos conceptuales, procedimentales $y$ actitudinales.

El 100\% de los docentes plantearon que evidencian en su planificación el medio que utilizarán para el desarrollo de sus contenidos; sin embargo, algunas veces no lograron utilizarlos por la carencia de equipos audiovisuales, ora "siempre que se deja escrito el uso del medio, es porque se necesita para determinada clase". Por otra parte, los docentes coinciden en que "si los medios no funcionan o no están disponibles, siempre recurren al Plan B"-implementación de otras estrategias-, aunque esto no fuere bien visto por los estudiantes en la mayoría de las ocasiones.

Es preciso destacar que los estudiantes en su mayoría hacían aportes significativos en la clase, con sentido crítico sus participaciones enriquecieron el proceso enseñanza en una interacción horizontal.

\section{Calidad del uso de los medios audiovisuales en el proceso enseñanza}

Se entendiendo por calidad a la eficacia y eficiencia en el desempeño de un sistema de gestiones realizadas por personas y máquinas, se disminuyen los costos y se incrementa la productividad, llegando a un producto final denominado calidad, que 
entra en el mercado de la competitividad. La calidad comienza en el señalamiento de métodos y objetivos.

Según las entrevistas, observaciones y grupos focales el 100\% de los docentes usan los medios audiovisuales en el proceso enseñanza-aprendizaje, y los discentes perciben y retienen mejor cuando los equipos son usados. Uno de los docentes dijo que al utilizar un determinado tipo de medio audiovisual le facilitaba porque de esa manera "les voy explicando, porque según dicen que si nosotros les explicamos al estudiante, algo así teóricamente aprende un 10\% y si le explicamos y lo está viendo aprende un 30\% porque están dos cosas: mira y escucha y relaciona la teoría". (Entrevista a docentes)

Siguen afirmando: "podemos decir que los medios son parte fundamental y ayuda de manera positiva para que el estudiante pueda captar más, a través de la explicación ya sea con dibujos, figuras, diapositivas, entre otros. Esto se presta para que la clase sea más llamativa, capte más la atención y que el estudiante sienta el interés que los docentes necesitan para desarrollar su contenido y así lograr un proceso concreto de enseñanza".

\section{Estrategia para aprovechar el uso de medios audiovisuales en el proceso enseñanza}

Los docentes deben estar anuentes a cambios sustanciales en la educación para que el proceso enseñanza sea significativo y los estudiantes puedan percibir mejor los contenidos, para ello es importante señalar que una estrategia es un conjunto de acciones que se llevan a cabo para lograr un determinado fin, a través del diseño de planes para alcanzar los objetivos con eficiencia y eficacia.

Según los resultados los docentes hacen un buen uso de los medios visuales como apoyo en sus tareas, y por otro lado las deficiencias en cuanto a su uso, abuso y manejo no contribuye a alcanzar los logros de un aprendizaje significativo.

Dentro de las estrategias que se sugieren en esta investigación para el buen uso de los medios audiovisuales se mencionan:

\section{Cómo utilizar el pizarrón}

El pizarrón es un medio visual que se utiliza con frecuencia. Los docentes deben determinar para qué clase es útil este medio y deben tener presente que se usa únicamente para escribir ideas principales, diagramas y dibujos. Si puede ocupar para plasmar la fecha, los contenidos a desarrollar durante la hora clase y el objetivo a concretar, luego determinar las zonas a utilizar durante el proceso de enseñanza. 


\section{Cómo utilizar el rota-folios}

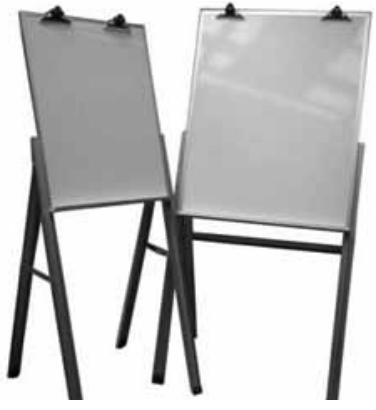

El rota-folios es un medio visual que se puede utilizar cuando el auditorio es pequeño. El rota-folios es muy útil para seguir la secuencia de la presentación de un tema; es importante señalar que el mismo permite que se vuelva a las ideas ya expuestas para aclarar dudas.

Los docentes al momento de planificar su clase, debe tener presente el medio de enseñanza a utilizar.

\section{¿Por qué aprovechar el retroproyector?}

El retroproyector es un aparato que requiere de energía eléctrica y que amplifica la imagen a través de un bombillo que sirve para iluminar a través de una lupa, que a su vez la proyecta en una secuencia de espejos móviles.

Los docentes al momento de determinar que este es el medio idóneo para el desarrollo del contenido, debe tener presente las ideas principales y los dibujos y valorar si este es el medio más idóneo para el proceso enseñanza.

\section{Beneficios de aplicar el Data-Show}

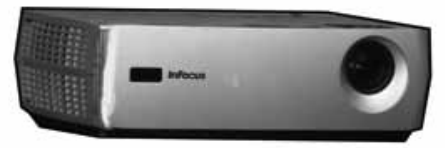

El uso del Data-Show es importante en el desarrollo de los temas, los docentes deben preparar con anticipación las diapositivas, revisar que los textos y la relación con las imágenes no estén recargadas. Insertar dibujos, fotografías, diagramas, animaciones, sonidos para que los estudiantes comprendan mejor lo expuesto, así se garantiza afianzar los conocimientos.

No deberá olvidarse que el Data-Show es una herramienta tecnológica avanzada, y por tal razón hay mecanismos digitales que se habrán de manipular con mucho tacto. El uso indebido de esta herramienta podría estropear uno de estos aparatos que fluctúa en los mercados alrededor de mil dólares.

El uso de esta herramienta en el salón de clase es meramente para apoyarse al momento de explicar los contenidos, en las diapositivas se plasman sólo las ideas más importantes para después desarrollarlas.

- Tener en cuenta que PowerPoint no es una herramienta autónoma.

- Asegúrese de que sus comentarios verbales resulten igualmente convincentes como la presentación expuesta de forma digital. 


\section{EDUCACIÓN}

- Las presentaciones más eficaces en PowerPoint deben ser sencillas: Reduzca al mínimo las cifras en las diapositivas.

- No lea literalmente la presentación de PowerPoint.

- PowerPoint también resulta en este caso más eficaz como acompañamiento visual de la palabra. Utilice colores brillantes.

- No limite la presentación a lo que ofrece PowerPoint. Utilice imágenes y gráficos externos, incluso vídeo, para mayor variedad y atractivo visual.

- Realice modificaciones sin reparos antes de la presentación.

- No pierda nunca la perspectiva de lo que quiere enseñar.

Según afirma Cebrian (200o), para un óptimo aprovechamiento de los medios audiovisuales es necesario que se den conjuntamente tres elementos: "Equipamiento audiovisual completo; calidad del manejo de los medios y formación en el uso de los medios. Por otra parte, para desarrollar una clase en las instituciones de Educación Superior, continúa aclarando, será necesario preparar con anticipación los extractos de las teorías y así usar adecuadamente los medios audiovisuales.

Desde la óptica de Cebrian, es que se hace esta propuesta para aprovechar los medios audiovisuales en todo el sentido de la palabra, principalmente en la Educación Superior.

\section{Conclusiones}

1. Los docentes coinciden en que la tecnología es útil en el proceso académico porque ayuda a mantener la atención en los estudiantes, además que permite hacer uso de diversas técnicas facilitando mayor comprensión y fijación del aprendizaje.

2. Algunos docentes se rehúsan a usar la tecnología por temor de estropear los aparatos que son muy costosos, por la falta de sensibilización y la importancia que le dan al uso de los mismos. También incide la formación que ellos recibieron, la cual tratan de implementar en el aula.

3. La falta de pericia en el manejo de equipos audiovisuales por parte de los docentes de la carrera de Ingeniería en Zootecnia, incide en la calidad de la utilización de los recursos tecnológicos que la sociedad demanda a nivel educacional.

4. Estudiantes y docentes coinciden que al usar los medios audiovisuales, el salón de clase se vuelve dinámico, activo y participativo en su mayoría; es necesario destacar que el uso adecuado de los medios audiovisuales ayuda a que los procesos de educación logren su fin.

5. El uso de diferentes medios audiovisuales incentiva a los estudiantes a sumergirse en la profundización de los contenidos, por su particular forma de visión, al usar 
medios novedosos e informáticos los estudiantes logran asimilar más rápido los contenidos en las diversas asignaturas que se imparten.

6. El predominio del enfoque tradicional en algunos docentes está presente en las aulas de clases. Hay alguna resistencia al cambio y temor al uso de nuevas tecnologías, aunque la URACCAN ha realizado capacitaciones con los docentes para que mejoren en el uso de las nuevas tecnologías.

7. Los sentidos (audición, visión y tacto) son fundamentales en el proceso enseñanzaaprendizaje, pues juegan un papel fundamental en la educación.

8. Las estrategias en el proceso enseñanza son de suma importancia y los docentes deben tomar en cuenta para que se usen de forma apropiados los medios, sirvan de apoyo para el desarrollo de los contenidos en los salones de clases y así aprovechar al máximo su fin.

\section{Lista de referencias}

Aguilar J. y Díaz, F. (1992). Proyecto de Educación para los medios Diagnóstico psicopedagógico en la educación básica.

Cabera, J. (1991). Producción o producciones audiovisuales en el terreno educativo: El siglo que viene, 11, 19-22.

Cabero, Julio (1999). Tecnología Educativa. Síntesis, Paidós, Madrid.

Cabero Julio (2004). La investigación en tecnología de la Educación. Barcelona, Paidós.

Castaño, C. (1992). Análisis y evaluación de las actitudes de los profesores hacia los medios de enseñanza. Sevilla, Facultad de Filosofía y CC. de la Educación, Tesis doctoral inédita.

Castañeda M, (1978). Los medios de comunicación y la Tecnología en la Educación. México, Trillas, pp 500.

Cebrian Herrera, M. (1992). Las nuevas tecnologías en la Educación. Santander, ICE de la Universidad de Cantabria.

Flores, R. et al. (1988). Hacia una pedagogía del conocimiento. Mc Graw-Hill.

Gardner, Howard (1983). Frames of MInd: The Theory of Multiple Intelligences. New York: Basic.

Poole, B. (1999). Tecnología educativa: "Lo que las investigaciones dicen sobre el uso de la tecnología informática para la enseñanza aprendizaje”. 2 da. Edición. 